\title{
PERANCANGAN SISTEM APLIKASI KEPENDUDUKAN KELURAHAN GANDUL BERBASIS JAVA DESKTOP
}

\author{
Ahmad Rizal ${ }^{1}$, Rudi Prasetya ${ }^{2}$ \\ Program Studi Teknik Informatika, Fakultas Teknik dan Ilmu Komputer, \\ Universitas Indraprasta PGRI \\ Jalan Raya Tengah No 80, Kelurahan Gedong, Pasar Rebo, Jakarta Timur \\ ahmadrizal0222@gmail.com ${ }^{1}$, rudiprasetya1@ gmail.com ${ }^{2}$
}

\begin{abstract}
Abstrak
Sistem aplikasi pendataan penduduk dikelurahan sampai saat ini masih banyak yang menggunakan sistem manual yaitu menggunakan Microsoft excel, dimana data-data serta berkas-berkas penduduk masih banyak yang berbentuk arsip atau dokumen. Hal ini menimbulkan beberapa kendala yang cukup merepotkan, terutama pada pencarian data yang cukup lama, danpenyimpanan data lama yang tidak beraturan sehingga terjadi pertumpukan berkas pada kantor kelurahan.Adapun tujuan penelitian ini dilakukan adalah untuk merancang sistem yang dapat memudahkan admin kelurahan dalam melayani masyarakat agar lebih cepat dan efisien, sehingga dengan adanya sistem aplikasi kependudukan kelurahan Gandul yang berbasis java desktopdapat mambantu staf dan admin kelurahan dalam melayani penduduk.Penelitian ini memiliki tujuan yaitu untuk membantu kelurahan Gandul agar terkomputerisasi dengan menggunakan metode grounded research, dimana metode grounded research mengharuskan membuat sebuah perancangan sistem informasi berdasarkan fakta dan data dilapangan. Sistem aplikasi kelurahan Gandul ini dirancang dengan menggunakan NetBeans IDE 8.0.2, xampp dimana phpMYAdmin sebagai operator database, MySQL sebagai database.Sistem aplikasi ini dirancang dengan alur dan desain antarmuka yang sederhana sehingga admin kelurahan lebih mudah menggunakan sistem aplikasi ini.Hasil penelitian ini diharapkan dapat membantu admin kelurahan dalam hal pengelolaan data kependudukan pada kelurahan Gandul.
\end{abstract}

Kata Kunci :Sistem aplikasi, kependudukan, Java desktop

\begin{abstract}
Until now, there are still many population data collection application systems in the urban village that use the manual system, namely using Microsoft Excel, where there are still many population data and files in the form of archives or documents. This causes several problems that are quite inconvenient, especially in searching for data that is quite long, and the storage of old data is irregular, resulting in piles of files at the urban village office. The purpose of this research is to design a system that can make it easier for village administrators to serve the community more quickly and efficiently, so that with the Gandul urban village population application system based on java desktop, it can help village staff and admins in serving the population. to help the Gandul urban village to be computerized using the grounded research method, where the grounded research method requires making an information system design based on facts and data in the field. Gandul urban village application system is designed using NetBeans IDE 8.0.2, xampp phpMYAdmin as database operator, MySQL as database. This application system is designed with a simple flow and interface design so that it is easier for urban village admins to use this application system. The results of this study are expected to help the village admin in terms of managing population data in the Gandul urban village.
\end{abstract}

Keywords: Application systems, Population, Java desktop

\section{PENDAHULUAN}

Perkembangan sistem informasi dari waktu ke waktu selalu mengalami peningkatan karena perubahan zaman yang semakin modern. Perubahan ini membuktikan kebutuhan manusia akan informasi semakin tinggi dan sudah menjadi kebutuhan pokok untuk kehidupan sehari-hari. Perkembangan ini sangat berpengaruh besar dalam upaya menyampaikan informasi yang akurat dan mudah.Jumlah penduduk dari tahun ke tahun mengalami peningkatan. Peningkatan jumlah penduduk ini membuat proses pengolahan data kependudukan mengalami kesulitan. Data kependudukan meliputi berbagai aspek, yang dalam pengolahannya membutuhkan perancangan 
sistem atau aplikasi terkendali untuk mempermudah pengolahan data tersebut. MenurutArif(2016)dalam bukunya yang berjudul bahan ajar perancangan teknik industri mengungkapkan: Perancangan menggambarkan rencana umum suatu kegiatan rancangan proyek dan aktivitas - aktivitas khusus yaitu teknik atau metode - metode dalam merancang sesuatu. Menurut Tyoso(2016:6)dalam bukunya yang berjudul sistem informasi manajemen mengungkapkan : Sistem merupakan suatu kumpulan dari komponen - komponen yang membentuk satu kesatuan. MenurutAndi(2015:1)Aplikasi adalah suatu program yang siap untuk digunakan yang dibuat untuk melaksanankan suatu fungsi bagi pengguna jasa aplikasi serta penggunaan aplikasi lain yang dapat digunakan oleh suatu sasaran yang akan dituju. Menurut Faqih(2010:7) dalam bukunya yang berjudul kependudukan terori, dakta dan masalah mengungkapkan : Kependudukan atau Demografi adalah ilmu yang mempelajari persoalan dan keadaan dinamika kedudukan manusia, meliputi didalamnya ukuran, struktur dan distribusi penduduk. Menurut Nofriansyah(2018) Kelurahan yaitu lembaga pemberdayaan masyarakat (LPM) yang merupakan lembaga kemasyarakatan yang telah berperan aktif dalam pembangunan sebagai mitra pemerintah dan pihak - pihak lain. Kelurahan Gandul Depok adalah salah satu instansi pemerintah daerah yang bergerak dibidang pelayanan masyarakat.Menangani berbagai kegiatan seperti penerbitan dokumen penting, kependudukan dan pencatatan sipil dengan diperlukannya suatu sistem terkomputerisasi dalam berbagai keperluan.Pengolahan data penduduk ini membutuhkan adanya komputer dalam menjalankan kegiatan, dan untuk menyelesaikan masalah yang dihadapi serta mengurangi tingkat kesalahan manusia (human eror) dalam memasukkan data.Kegiatan pengolahan data penduduk di Kelurahan Gandul Kota Depok belum sepenuhnya terkomputerisasi, hal ini mengakibatkan pendataan penduduk kurang efisien dalam menyajikan informasi. Dalam penyimpanan data - data berupa arsip masih di tumpuk yang menimbulkan proses pemasukan dan pencarian data relatif lama, keamanan kurang terjamin, dan besar kemungkinan data akan hilang atau terselip. Seiring berjalannya waktu, semakin lama data-data penduduk pada instansi pemerintah semakin bertambah banyak. Sebagai solusi dari permasalahan di atas, diharapkan dengan adanya perancangan sistem pengolahan data penduduk dapat mengurangi permasalahan yang ada.Dari hasil penelitian inisistem aplikasi kependudukan pada kelurahan Gandul bertujuan untuk menghasilkan perancangan sistem aplikasi data penduduk berbasis java desktop, untuk membantu kepala kelurahan, maupun para staf pada kelurahan tersebut dalam menyajikan data penduduk sehingga dapat memenuhi kebutuhan dalam pencarian dan penyajian informasi dengan proses yang cepat dan tepat, memperlancar proses penyimpanan, dan laporan arsip data penduduk pada instansi pemerintah.

\section{PENELITIAN RELEVAN}

Untuk membuat dasar penelitian maka peneliti mencari penelitian yang berhubungan dengan topik yang peneliti bahas yaitu mengenai sistem informasi kependudukan. Penelitian yang dilakukan oleh (Iriani, 2013) dengan judul sistem informasi data penduduk pada desa bogoharjo kecamatan ngadirojo kabupaten pacitan. Dalam penelitian ini dijelaskan bahwa sistem informasi yang dipakai masih menemui beberapa kendala dalam memproses data kelahiran, kematian, pendatang dan pindah serta pembuatan laporan masih dalam kesulitan. Untuk mengembangkan sistem tersebut maka dirancanglah sebuah sistem yang bertujuan untuk mempercepat proses pendataan serta pembuatan laporan bulanan. Diharapkan dengan adanya sistem tersebut maka petugas merasa terbantu dalam mencari dan mengelola data penduduk.

Penelitian yang dilakukan oleh (Isabella, 2019) yang berjudul perancangan sistem pengolahan data penduduk pada kelurahan cipedak Jakarta Selatan.Dari hasil penelitian inisistem pengolahan data penduduk pada kelurahan agar bertujuan untuk mengetahui sistem informasi pengolahan data penduduk yang efektif dan efisien.Hasil dari penelitian ini adalahdengan perancangan sistem pengolahan data penduduk tersebut diharapkanstaf kelurahan dapat bekerja dengan cepat, tepat dan akurat.Agar pada saat mengolah data penduduk tersebut tidak ada kesalahan dalam penginputan.

Penelitian yang dilakukan oleh (Barokati, 2018) yang berjudul perancangan sistem informasi kependudukan RT012/02 kelurahan Gandaria Selatan berbasis java. Dari hasil dari penelitian sistem informasi kependudukan tersebut dapat memudahkan staff RT dalam mendata warga.Hasil 
dari penelitian ini adalah terciptanya aplikasi perancangan sistem informasi berbasis java yang berguna untuk informasi data kependudukan.

Penelitian keempat dilakukan oleh (Fujiyati dan Sukadi, 2015) dengan judul sistem informasi pengolahan data kependudukan desa purwoasri. Dalam penelitian ini dijelaskan bahwa sistem informasi yang dipakai masih menemui beberapa kendalayaitu yang masih sering terjadi kesalahan dalam mengolah atau mendata penduduk, dikarenakan dalam pengolahanya masih dengan proses yang konvensional. Untuk mengembangkan sistem tersebut maka dirancanglah sebuah sistem yang bertujuan untuk menghasilkan program aplikasi pengolahan data penduduk di DesaPurwoasri.Diharapkan dengan adanya sistem tersebut memberikan gambaran kepada petugas Kantor Desa Purwoasri tentang aplikasi pengolahan data penduduk di Desa Purwoasri secara terkomputerisasi.

Penelitian kelima dilakukan oleh (Pauziah, 2013) dengan judul perancangan sistem pendataan penduduk pada kelurahan cililitan jakarta timur berbazis delphi. Dalam penelitian ini dijelaskan bahwa sistem informasi yang dipakai masih menemui beberapa kendala yaitu sistem pendataan pendudukmasih dilakukan secara manual seperti pembuatan laporan dan pencatatan. Untuk mengembangkan sistem tersebut maka dirancanglah sebuah sistem yang bertujuan untuk menciptakan rancangan sistem pendataan penduduk secara komputerisasi,dimana sistem pendataan penduduk secara komputerisasi dapat membantu pihak kelurahan cililitan dan mengimplementasikan sistem informasi pendataan penduduk dalam mendata penduduk di Kelurahan Cililitan. Diharapkan dengan adanya sistem yang sudah terkomputerisasi diharapkan pekerjaan yang dilakukan dapat lebih mudah dan cepat dipergunakan dan Ketepatan waktu pelaporan secara tidak langsung akan memberikan pengaruh yang sangat besar pada peningkatan produktifitas dari kelurahan.

\section{METODE PENELITIAN}

\section{Observasi}

metode untuk mendapatkan data dengan melakukan pengamatan langsung, pencatatan dan pengumpulan data - data yang dilakukan pada lingkungan Kelurahan Gandul.

\section{Wawancara}

Metode wawancara dilakukan dengan tujuan untuk memperoleh data secara luas dan menyeluruh sesuai dengan kondisi saat ini.

\section{Langkah-langkah pengembangan sistem}

Metode pengembangan sistem yang peneliti gunakan dalam penelitian ini adalah metode waterfall. Metode waterfall ini sebenarnya adalah "LinearSquential Model", yang sering juga disebut dengan "Classic Life Cycle" atau model Waterfall. Adapun rancangan sistem ini harus mengikuti tahapantahapan pada metode yang digunakan yaitu metode Waterfall yang meliputi proses-proses sebagai berikut :

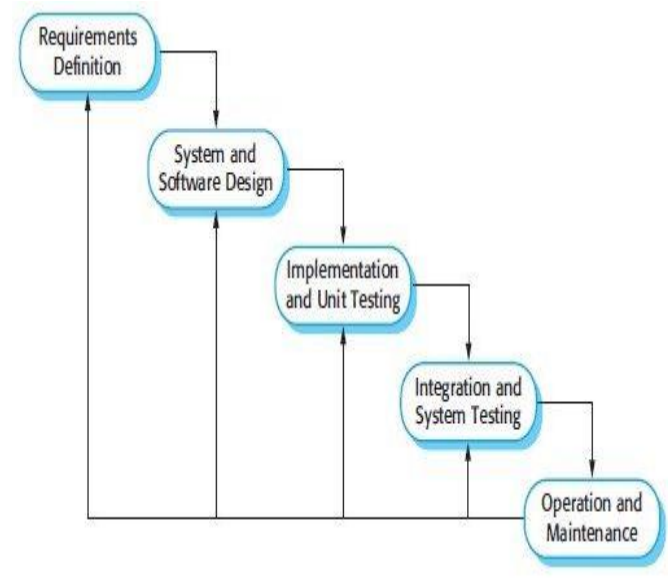

Gambar 1. Metode Waterfall 
a. Requirements Definition (Analisis data definisi kebutuhan)

Layanan batasan dan tujuan sistem ditentukan melalui konsultasi dengan user atau pemakai.

b. System and Software Design (Perancangan sistem dan perangkat lunak)

Proses perancangan sistem membagi persyaratan dalam sistem perangkat keras atau perangkat lunak. Kegiatan ini menentukan arsitektur sistem secara keseluruhan.Perancangan melibatkan identifikasi dan deskripsi abstrak sistem perangkat lunak yang mendasar.

c. Implementation and Unit Testing (Implementasi dan pengujian unit)

Pada tahap ini, perancangan perangkat lunak direalisasikan dengan program atau unit program.Pengujian ini melibatkan verifikasi bahwa setiap unit telah memenuhi spesifikasinya.

d. Integration and System Testing (Integrasi dan pengajuan sistem)

Program atau unit program individual diintegrasikan dan diuji sebagai sistem yang lengkap untuk menjamin bahwa kebutuhan sistem telah dipenuhi.

e. Operation and Maintenance (Operasi dan pemeliharaan)

Mengoperasikan program di lingkungannya dan melakukan pemeliharaan.Pemeliharaan mencakup koreksi dari berbagai error yang tidak ditemukan pada tahap-tahap sebelumnya, melakukan perbaikan atas implementasi unit sistem dan pengembangan layanan sistem dan persyaratan-persyaratan baru ditambahkan.

\section{HASIL DAN PEMBAHASAN}

\section{Analisis Permasalahan}

Pada sistem yang berjalan selama ini, masih terdapat permasalahan yang harus diperbaiki, atau disempurnakan sesuai dengan perkembangan teknologi dan program yang semakin berkembang ditambah perkembangan penduduk sekitar ruang lingkup Kelurahan Gandul semakin meningkat sehingga permasalahan-permasalahan yang timbul akan semakin memperlambat proses kinerja para pengurus instansi kelurahan.

\section{Diagram Konteks Sistem yang Diusulkan}

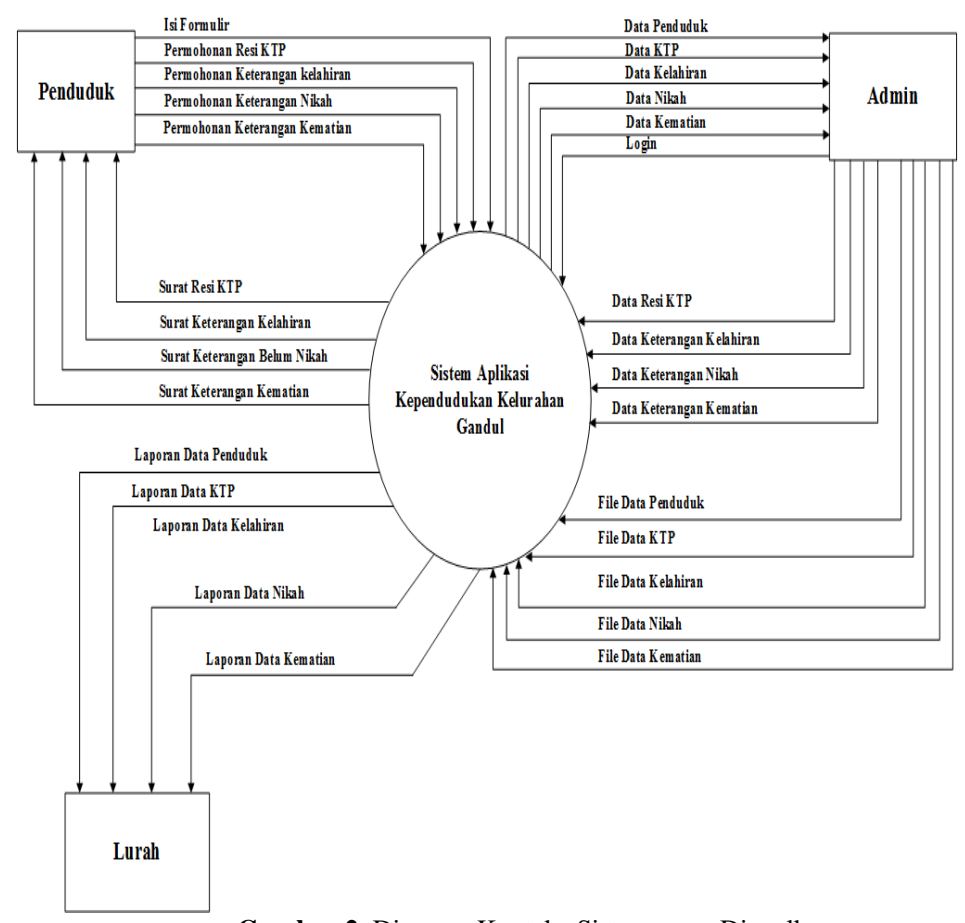

Gambar 2. Diagram Konteks Sistem yang Diusulkan 


\section{Entity Relationship Diagram (ERD)}

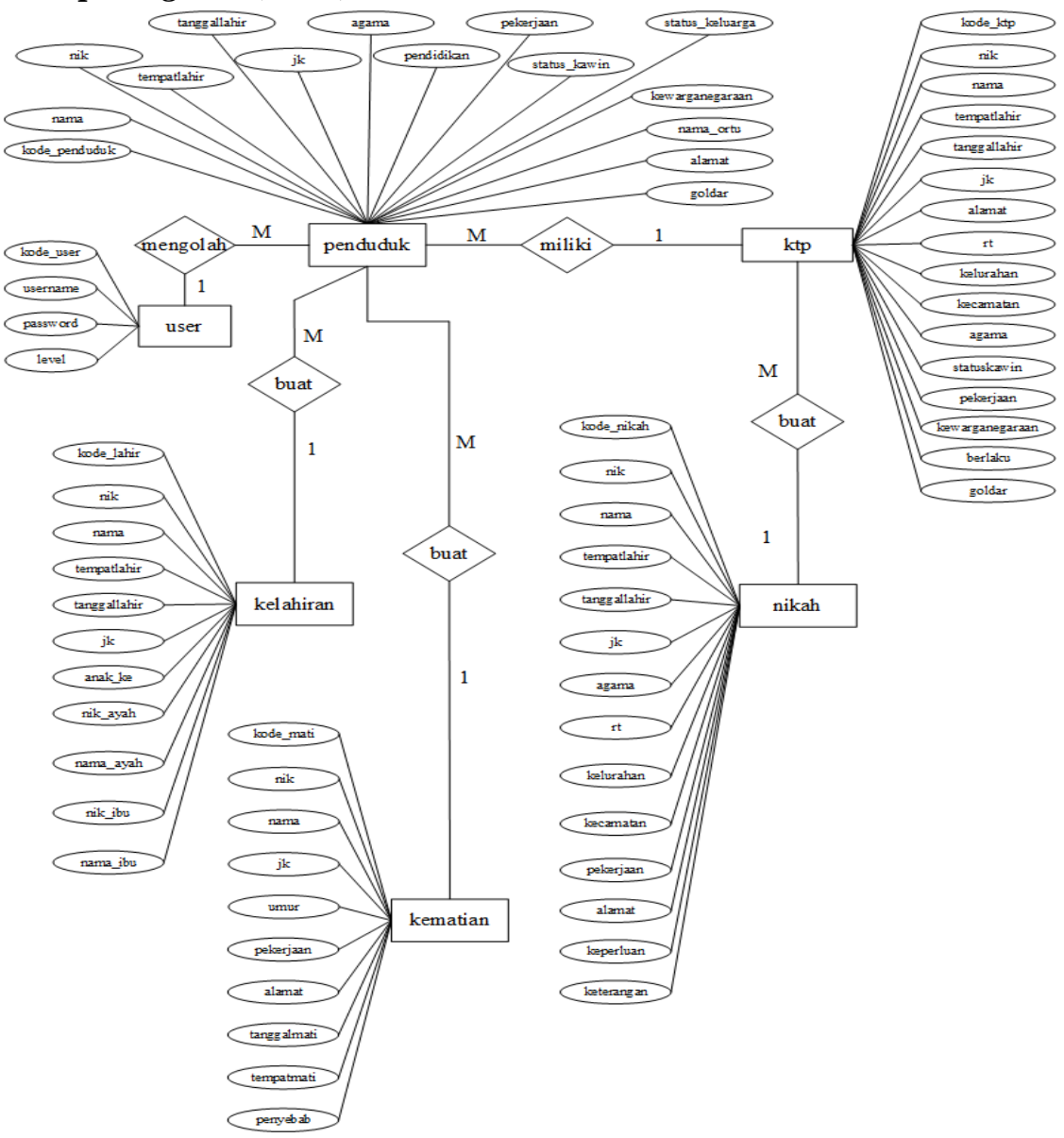

Gambar 3. Entity Relationship Diagram (ERD)

\section{Tampilan Aplikasi}

Berikut ini hasil Perancangan Aplikasi Kependudukan Kelurahan Gandul

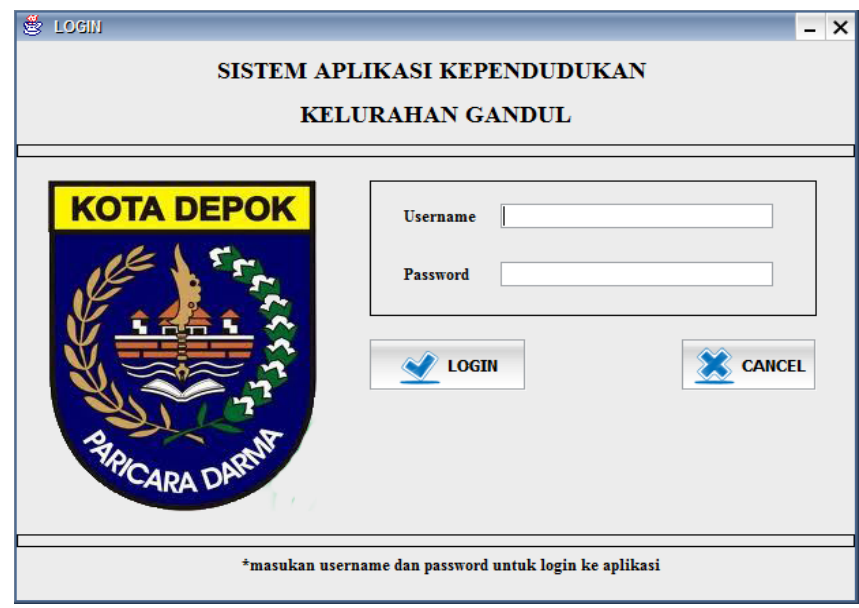

Gambar 4. Tampilan Menu Login

Pada gambar 4 diatas menampilkan form untuk login 


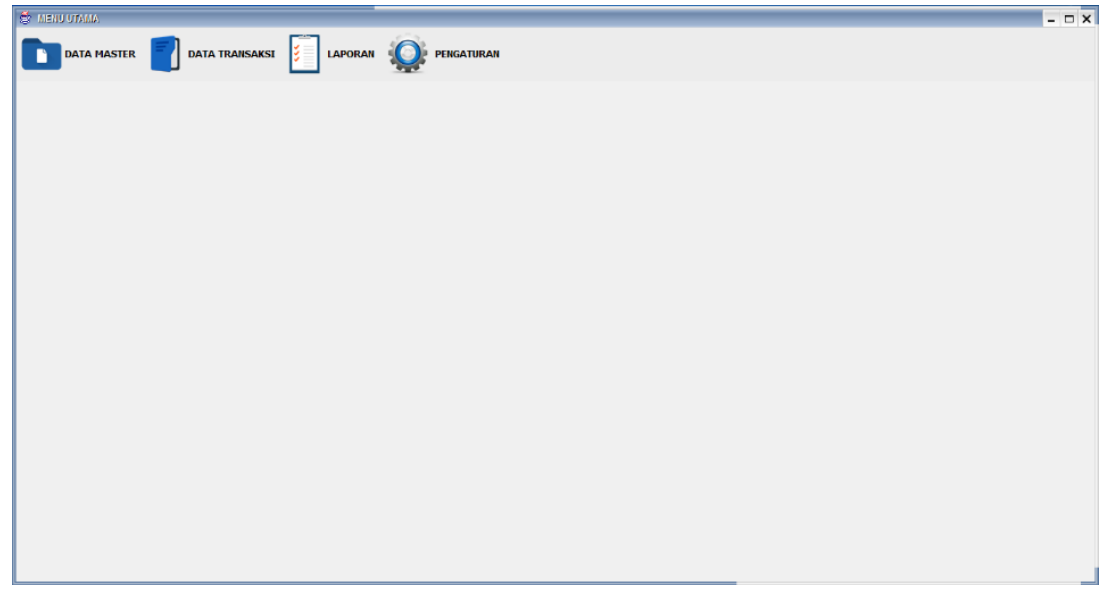

Gambar 5. Tampilan Layar Menu Utama

Pada layar ini terdapat data master, data transaksi, laporan dan pengaturan

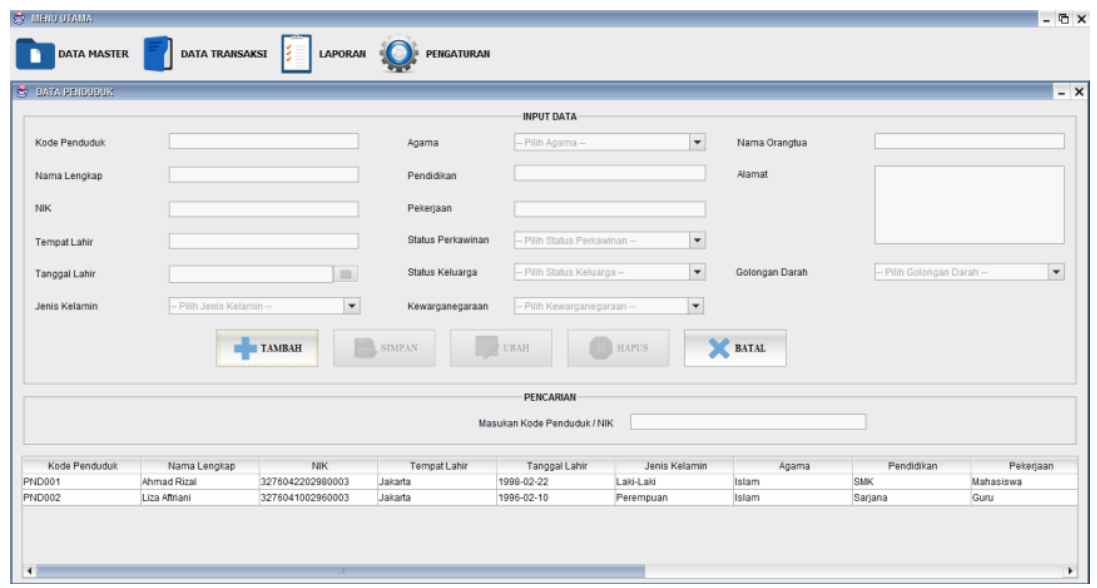

Gambar 6. Tampilan Layar Data Penduduk

Pada layar ini terdapat kode penduduk, nama lengkap, nik, tempat lahir, tanggal lahir, jenis kelamin, agama, pendidikan pekerjaan, status perkawinan, status keluarga, kewarganegaraan, nama orangtua, alamat, golongan darah

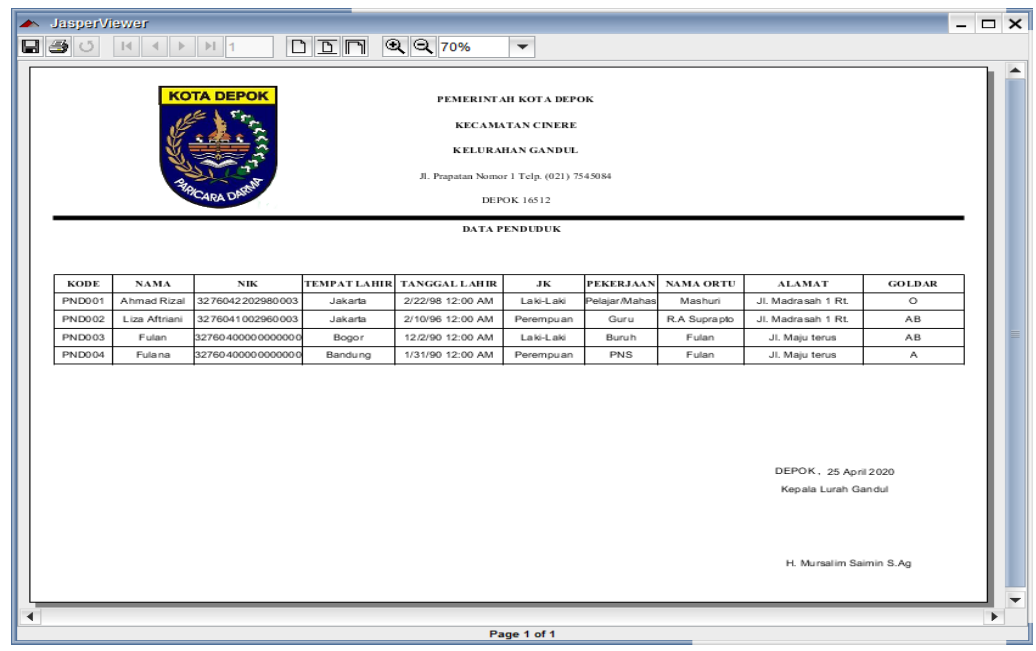

Gambar 7. Laporan Data Penduduk

Tampilan Outputlaporan data penduduk yang siap dicetak hasil dari inputdata penduduk. 


\section{SIMPULAN}

Berdasarkan uraian diatas dan anlisa, maka pada laporan penelitian ini yang berjudul "Perancangan Sistem Aplikasi Kependudukan Kelurahan Gandul Berbasis Java Desktop" dapat diambil kesimpulan sebagai berikut: Dengan menggunakan program berbasis java diharapkan akan meningkatkan efisiensi waktu dan efektifitas pekerjaan, dalam menyelesaikan masalah-masalah yang ada di lingkungan Kelurahan Gandul. Dengan adanya sistem baru ini diharapkan agar bisa mempermudah dan mempercepat admin dalam membuat surat maupun laporan, serta dapat menghindari duplikasi pada saat pengolahan datanya.

\section{DAFTAR PUSTAKA}

Andi, J. (2015). Pembangunan Aplikasi Child Tracker Berbasis Assisted - Global Positioning System ( A-GPS ) Dengan Platform Android. Jurnal Ilmiah Komputer Dan Informatika (KOMPUTA), 1(1), 1-8. elib.unikom.ac.id/download.php?id=300375

Arif, M. (2016). Bahan Ajar Rancangan Teknik Industri. Deepublish.

Barokati, A. A. (2018). Perancangan Sistem Informasi Kependudukan RT012/02 Kelurahan Gandaria Selatan Berbasis Java. Universitas Indraprasta PGRI.

Faqih, A. (2010). Kependudukan: Teori, Fakta dan Masalah. Deepublish.

Fujiyati, Y., \& Sukadi. (2015). Sistem Informasi Pengolahan Data Kependudukan. Journal Speed - Sentra Penelitian Engineering Dan Edukasi, 7(1), 1-15. http://ijns.org/journal/index.php/speed/article/view/1303

Iriani, D. P. dan S. (2013). Sistem Informasi Data Penduduk Pada Desa Bogoharjo Kecamatan Ngadirojo Kabupaten Pacitan. Indonesian Journal on Networking and Security, 2.

Isabella. (2019). Perancangan Sistem Pengolahan Data Penduduk pada Kelurahan Cipedak Jakarta Selatan. Universtitas Indraprasta PGRI.

Nofriansyah, D. (2018). Penelitian kualitatif: analisis kinerja lembaga pemberdayaan masyarakat kelurahan (2 Revisi). Deepublish.

Pauziah, U. (2013). Perancangan Sistem Pendataan Penduduk Pada Kelurahan Cililitan Jakarta Timur Berbazis Delphi. Faktor Exacta 6(3): 189-199, 6(3), 189-199.

Tyoso, J. S. P. (2016). Sistem Informasi Manajemen (1st ed.). Deepublish. 